\title{
Research on the Investment Pressure Testing of Power Grid Enterprises Based on Logistic Model
}

\author{
Junsong QIN, Jiao FAN, Dongxiao NIU \\ School of Business \& Management, North China Electric Power University, Beijing 102206
}

\begin{abstract}
The grid is the important fundamental facilities of national economy. With the feature of capital intensive, power grid investment bring about large risk to power grid enterprises. Thus it's necessary for power grid enterprises to conduct the investment pressure testing so as to ensure the smooth progress of investment. In this paper, it tried to build the pressure testing model by referring to the risk control method of banking industry. First, it analyzed the characteristics of the power grid investment and chose the key influence factors. Then it combined with the financial data of $Z$ province during year 2001 to 2013 and established the Logistic model of stress testing. Studies showed that the sales price of electricity and financing capability make important influence on investment capacity of power grid enterprises.
\end{abstract}

KEYWORDS: Power grid enterprise; Investment capacity; Logistic model; Pressure testing; Risk control

\section{INTRODUCTION}

Grid investment belongs to capital intensive industry with the characteristics of huge amount, long payback period and easily affected by macro factors[1]. Considering the social growing demand for electricity and the construction of competitive electricity market and special high-voltage power grid, the power grid investment will maintain in a high level[2-3]. However, power grid enterprises in China are still in a monopoly market. Due to the lack of competition, the government restricts the revenue of power grid enterprises into the income of electricity sale. Single income source and strict policy control made that the investment capacity of power grid enterprise is restricted.

Pressure test, as a method of risk management, has been proposed in 1990s. Since it has the advantage of estimating economic loss under abnormal market conditions, it has been widely used among national banks and financial institutions to carry out risk management[4]. The key lies in the pressure testing is to analysis the maximum capacity loss of investors when the scene of market pressure generated. Xiong Bo established the multivariate Logit model of macro-economic factors, the pressure testing on the regression results for scenario showed that GDP and the inflation rate is two important factors to affect the stability of banking system in China [5]. Li Jiang used default rate to reflect the credit risk of banking system, by establishing multi- liner regression model with selected macroeconomic variables, it proved that nominal GDP and inflation indicators significantly affected the banking system default rate[6].

This paper will extent the pressure test theory into power grid investment industry. By establishing the mathematical model, it can calculate the possibility of investment risk of power grid enterprises in extreme stress scenarios. The paper is organized as follows. In the next section, we propose the model that we research in this paper based on the theory, and some assumptions and steps are given. In Section 3, the empirical analyses based on the model are presented. Finally, we conclude our paper in section 4.

\section{LOGISTIC MODEL THEORY}

Effective stress testing method is the study of "abnormal but reasonable" economic impact, it is widely applied because of the forward-looking information can be provided in the extreme events. However, at present, the pressure test is limited to the inspection of the fragility of the banking system and part of the real estate industry investment risk, whose function has not been fully utilized. The power grid enterprise investment and investment in real estate industry have similar performance, and also be influenced by various macroeconomic 
factors, so it can be studied by using the Logistic model to analysis investment risk probability.

By identifying the key variables, Logistic model can provide support for the sensitivity analysis. Logistic regression requires the dependent variable $\mathrm{Y}$ as classification variables and the independent variables can be continuous variables, class variables or classification variables. Though various indexes affect the risk of power grid investment, the Logistic regression model can solve this problem effectively. The model assumes that the possibility of power grid enterprise investment risk is a function of a set of explanatory variables consisting of vectors. It can be used to carry on the data processing and the crisis of power grid enterprises probability estimation, and the probability is obtained by the maximum likelihood function.

\subsection{Model assumptions}

Some assumptions of Logistic regression model and linear regression are very similar.

(1)The data must be from a random sample;

(2)The dependent variable is determined as a function of independent variables;

(3)The Logistic regression is sensitive to multicollinearity among the independent variables because multi collinearity may cause errors in the expansion of standard.

However, the Logistic regression model has some different assumptions comparing with linear regression.

(1)The Logistic regression model of the dependent variable is a two classification variables, this variable can take only 0 or 1 two values. The focus of the study lies in the event of conditional probability, namely $\mathrm{P}$;

(2)The Logistic regression model for the relationship between variables and the independent variables are nonlinear;

(3)The Logistic regression model is not required as in linear regression model as the identical distribution assumption;

(4)The Logistic regression model has no assumptions regarding the distribution condition variables, each variable can be continuous, discrete or virtual, and also does not require the assumption of multivariate normal distribution exists among them.

\subsection{Construction of Logistic model}

In Logistic model, the following hypothesis presents the non-linear relationship between the occurrence probability of dependent variable and each influencing factor variable.

$$
\mathrm{p}_{\mathrm{i}}(\mathrm{Y}=1)=\frac{\exp \left(a_{0}+\sum_{k=1}^{k} a_{k} X_{k i}\right)}{1+\exp \left(a_{0}+\sum_{k=1}^{k} a_{k} X_{k i}\right)}
$$

Transform into:

$$
p(Y=1)=\frac{1}{1+e\left[-\left(a_{0}+\sum_{k=1}^{k} a_{k} X_{k i}\right)\right]}
$$

Where $P_{\mathrm{i}}$ is the undetermined probability, $X_{k i}$ is independent variable, $a_{0}$ is constant, and $a_{1}, a_{2}, \ldots a_{k}$ are regression coefficients.

Logistic regression model is a probabilistic model of nonlinear regression. The value of the equation is between 0 and 1 , which is the limit of the probability. We made the logit transform as following linear equation.

$$
\ln \left(\frac{\mathrm{p}_{\mathrm{i}}}{1-\mathrm{p}_{\mathrm{i}}}\right)=a_{0}+\sum_{k=1}^{k} a_{k} X_{k i}
$$

\subsection{Steps of Logistic regression}

When we processed logistic regression, there are several steps. First, we should identify the influence factors of grid investment and carry out the colinearity test to screen factors. Then we can put data into Logistic model and obtain regression coefficients. After the significance test, we can modify the model from variables. If the model have gotten satisfied fitting results, we can analysis output and apply it into actual problems. The steps of Logistic regression model are shown in figure 1.

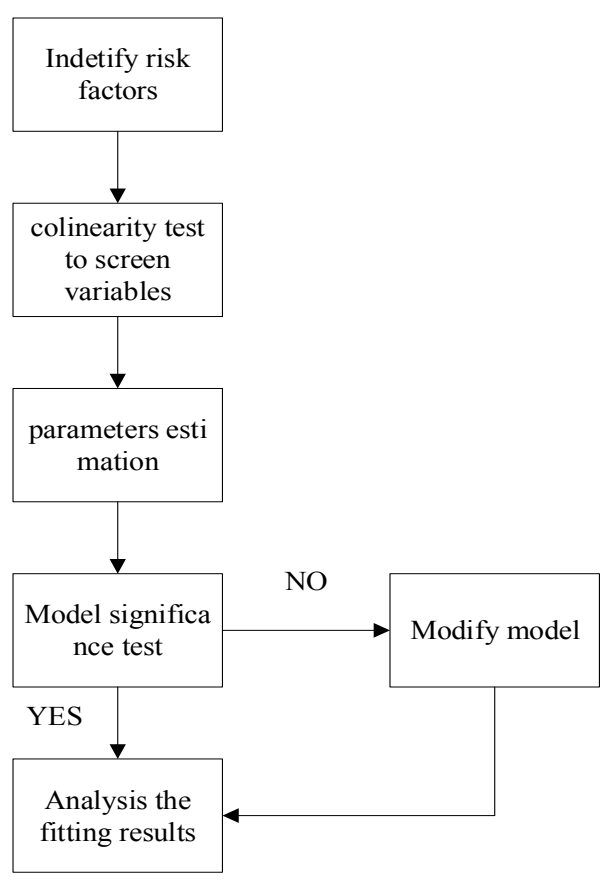

Figure1. Steps of logistic regression 


\section{EMPIRICAL ANALYSIS}

The investment ability means the capital quantity the power grid enterprises can provide for grid investment. This paper will apply logistic theory to establish the pressure test model of $Z$ Province on the base of analyzing risk factors. Through that, we can find the key factors and make suggestions about risk management for power grid enterprises

\subsection{Risk factors of investment in power grid}

There are many factors that affect the investment ability of power grid enterprises, and each factor will have an impact on the direction of investment, the investment amount and investment risk. These factors included electricity sale, purchase cost, financing ability and so on [7-8]. Considering the factors influencing the investment ability of grid is numerous, we clustered single factors after referring to the expert consultation and identified six independent variables, including depreciation(X1), sale price of end use(X2), electricity sale(X3), electricity purchase cost (X4),financing capability(X5) and GDP of secondary industry(X6). And we select the profit rate of asset as the dependent variable, since it can reflect the production and management state of enterprises comprehensively.

Return on assets =total profits/average total assets, and table 1 showed the Return on assets in $\mathrm{Z}$ Province during year 2003 to 2013.

Table 1 Return on assets in Z Province from 2005 to 2013

\begin{tabular}{|c|c|c|c|c|c|c|c|c|c|c|c|}
\hline Year & 2003 & 2004 & 2005 & 2006 & 2007 & 2008 & 2009 & 2010 & 2011 & 2012 & 2013 \\
\hline Return on assets & $0.33 \%$ & $0.75 \%$ & $0.81 \%$ & $1.61 \%$ & $2.60 \%$ & $0.23 \%$ & $0.09 \%$ & $2.40 \%$ & $2.22 \%$ & $2.82 \%$ & $2.54 \%$ \\
\hline $\mathrm{Y}$ & 1 & 1 & 1 & 0 & 0 & 1 & 1 & 0 & 0 & 0 & 0 \\
\hline
\end{tabular}

Consider the dependent variable in the Logistic regression model can be only 0 or 1 , this paper calculated the average value of return on assets over the past 20 years in $\mathrm{Z}$ Province is $1.5 \%$. And we think that when an annual profit rate is higher than $1.5 \%$, the power grid investment is booming with lower investment risk and the dependent variable is set to 0 ; when it is less than $1.5 \%$, we set the dependent variable $\mathrm{Y}$ as 1 which means the slump in investment.

\subsection{Variables screening and parameters estimation}

\subsubsection{Colinearity test}

It is much likely to exist high correlation between primary variables, therefore, it's necessary to conduct correlation test to eliminate the impact of colinearity before regression. In this paper, we selected 0.9 as the standard of correlation. Table 2 showed the self-correlation coefficients of independent variables. We can see that variable X1 has high correlation with $\mathrm{X} 2, \mathrm{X} 3$ and $\mathrm{X} 6$. The coefficients are $0.97,0.96$ and 0.96 respectively, which are all higher than 0.9 , so we removed variable X1 out of Logistic model. Then we proceeded colinerarity test with left variables and found that the coefficients between variable X6 and $\mathrm{X} 2, \mathrm{X} 3$ are still higher than 0.9 , so we screened X6 and took $\mathrm{X} 2, \mathrm{X} 3, \mathrm{X} 4, \mathrm{X} 5$ as independent variables into Logistic model.
Table 2 Self-correlation coefficients of independent variables

\begin{tabular}{|l|l|l|l|l|l|l|}
\hline & $\mathrm{X} 1$ & $\mathrm{X} 2$ & $\mathrm{X} 3$ & $\mathrm{X} 4$ & $\mathrm{X} 5$ & $\mathrm{X} 6$ \\
\hline $\mathrm{X} 1$ & 1 & & & & & \\
\hline $\mathrm{X} 2$ & 0.974321 & 1 & & & & \\
\hline $\mathrm{X} 3$ & 0.969393 & 0.98048 & 1 & & & \\
\hline $\mathrm{X} 4$ & 0.7734 & 0.730803 & 0.837035 & 1 & & \\
\hline $\mathrm{X} 5$ & 0.608943 & 0.647722 & 0.720167 & 0.878901 & 1 & \\
\hline $\mathrm{X} 6$ & 0.957768 & 0.969455 & 0.996358 & 0.853553 & 0.743251 & 1 \\
\hline
\end{tabular}

\subsubsection{Parameters estimation}

In the Logistic model, we set $\mathrm{P}=0.1$ as the significance level and adopted the method of compulsory entered to process the regression., Table 3 showed the regression results by SPSS software.

Table 3 Logistic regression results

\begin{tabular}{|l|l|l|l|l|l|l|}
\hline \multicolumn{2}{|c|}{} & B & S.E, & Wals & df & Sig. \\
\hline \multirow{4}{*}{ step 1 1} & X2 & 4.984 & 14.101 & .125 & 1 & .024 \\
\cline { 2 - 7 } & X3 & -3.309 & 16.520 & .040 & 1 & .041 \\
\cline { 2 - 7 } & X4 & 1.630 & 5.945 & .075 & 1 & .084 \\
\cline { 2 - 7 } & $\mathrm{X} 5$ & -3.465 & 3.466 & 1.000 & 1 & .017 \\
\cline { 2 - 7 } & constant & -1.138 & 1.115 & 1.042 & 1 & .007 \\
\hline
\end{tabular}

Table 3 shows the regression coefficients of each variable, we can see that all regression coefficients have passed the $\mathrm{P}$ value test in the $90 \%$ confidence level. The fitting of the Logistic regression equation is as following.

1

$\mathrm{p}_{\mathrm{i}}(\mathrm{y}=1)=\frac{1}{1+\exp (1.138-4.984 X 2+3.309 X 3-1.630 X 4+3.465 X 5)}$ 


\subsubsection{Model significance test}

Table 4 and Table 5 showed the fitting effect of Logistic regression model. The smaller the $-2 \log$ likelihood values is, the better the fitting results. And two pseudo decision coefficients showed the ratio of the independent variable explaining the variability of the dependent variables to the total variation. From Table 4 , we can see the $-2 \log$ likelihood value is 0 and Nagelkerke R2 is 0.98 , which means the independent variables can explain the variability of the dependent variables for $98 \%$ of the total variability of dependent variable. And Table 5 demonstrated the Hosmer-Lemeshow test, whose null hypothesis is complete fitting. We can see that the Sig value is 0.534 , which means we can't reject the null hypothesis, namely the model fitted values is satisfactory.

Table 4 Model index value

\begin{tabular}{|l|l|l|l|}
\hline Step & $-2 \log$ likelihood value & Cox \& Snell $\mathrm{R}^{2}$ & Nagelkerke $\mathrm{R}^{2}$ \\
\hline 1 & $.000^{\mathrm{a}}$ & .848 & 0.980 \\
\hline
\end{tabular}

Table 5 Hosmer and Lemeshow Inspection

\begin{tabular}{|l|l|l|l|}
\hline Step & $\mathrm{R}^{2}$ & $\mathrm{df}$ & Sig. \\
\hline 1 & 6.052 & 7 & .534 \\
\hline
\end{tabular}

\subsection{Model conclusion}

From regression equation of investment pressure test, we can know electricity purchase cost(X4) has positive effect on investment risk, while sale price of end user(X2), electricity sale(X3) and financing capability(X5) has negative effect on risk, which means when the price, sales or financing capability are higher ,the investment ability risk will be lower. And among four independent variables, we can know sale price of end user(X2) has the greatest impact on investment risk, followed by financing capability, the sale of electricity and the electricity purchasing cost. Next we can choose the key factors to proceed sensitivity analysis and get quantitate results.

\section{CONCLUSION}

This paper learned from the successful experience in the risk management of commercial banks and real estate enterprises and apply pressure test into grid investment. By analysising the characteristics of the power grid investment, it has constructed the Logistic model with selected variables. The study proved that sale price of end user and financing capability have significant impact on investment risk. Also, we put forward suggestions that since the electricity price is restricted by government, when the capital quantity can not satisfy the grid investment demand, the power grid enterprises can improve the risk control ability by reasonable financing strategy.

\section{ACKNOWLEDGMENTS}

This work was partially supported by the Natural Science Foundation of China (71071052) and (71471059)

\section{REFERENCES}

[1] Guo Ji-wei, Song Wei-dong.Analysis of Power Grid Investment in USA and Revelations to China. Electric Power Technologic Economics.20095(21):68-72

[2] Zhang Pei-li, Zheng Huai, Chi Feng. Analysis of grid investment of East China Power Grid during the 10th FiveYear period. East China Electric Power.2007.2(35):45-48

[3] Xia Huali, YE Jinshu. Grid Investment Fluctuation Factors and Growth Effect. Power System Technology. 2011. (35): $12-20$

[4] Wang Qian-rong. Stress Test on Real Estate Development Investment Based on Logistic Regression Model. Liao Ning: Northeastern University.2010

[5] Xiong Bo. Evaluation on stability of China banks. Chengdu: financial university of southwestern China, 2006

[6] Li Jiang, Liu Liping. China commercial bank system credit risk evaluation- study based on macro pressure test. Modern economic science. 2008.30(6): 66-73+124.

[7] Payne J E. A survey of the electricity consumption-growth literature. Applied Energy, 2010(87):723-731

[8] Zhu Jun, Zhuang Xin-tian, Wang Qianrong. Study on the development of China's real estate investment pressure test based on th8e Logistic model. Shanghai management Science. 2012.4(34):40-43 